\title{
A systematic review on diagnostics and surgical treatment of adult right-sided Bochdalek hernias and presentation of the current management pathway
}

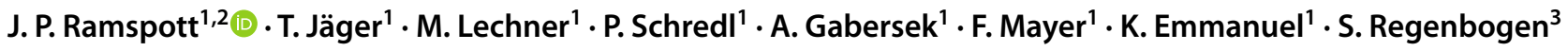

Received: 6 March 2021 / Accepted: 10 June 2021 / Published online: 3 July 2021

(c) The Author(s) 2021

\begin{abstract}
Purpose Bochdalek hernia is a congenital diaphragmatic hernia. The incidence in adults is estimated around $0.17 \%$. Rightsided hernias are much more seldom than left-sided ones because of faster closure of the right pleuroperitoneal canal and the protective effect of the liver. Due to its rarity, there have been no large prospective or retrospective studies following great need for evidence-based diagnostics and treatment strategies. In this systematic review, we evaluated the current evidence of diagnostics, treatment, and follow-up of adult right-sided Bochdalek hernias.

Methods According to the Preferred Reporting Items for Systematic Reviews and Meta-Analyses (PRISMA) guidelines a systematic literature review was conducted in PubMed and Cochrane library from 2004 to January 2021. The literature search included all studies with non-traumatic right-sided Bochdalek hernias. Literature on left- or both-sided, pregnancy-associated, pediatric, and other types of hernias were explicitly excluded. Quality assessment of the included studies was performed.

Results Database search identified 401 records. After eligibility screening 41 studies describing 44 cases of right-sided nontraumatic Bochdalek hernias in adulthood were included for final analysis. Based upon the systematic literature review, the current diagnostic, therapeutic, and follow-up management pathway for this rare surgical emergency is presented.

Conclusion This systematic review underlined that most studies investigating management of adult non-traumatic right-sided Bochdalek hernias are of moderate to low methodological quality. Hernias tend to occur more frequently in middle-aged and older women presenting with abdominal pain and dyspnea. A rapid and accurate diagnosis following surgical repair and regular follow-up is mandatory. High-quality studies focusing on the management of this rare entity are urgently needed.
\end{abstract}

Keywords Bochdalek hernia $\cdot$ Hernia $\cdot$ Algorithm $\cdot$ Repair $\cdot$ Mesh $\cdot$ Suture

\section{Introduction}

Diaphragmatic hernias may occur congenitally or secondarily due to trauma allowing thoracic herniation of abdominal contents. Normally, diaphragmatic formation separates the thoracic cavity from the peritoneal one around week 8 of gestation [1]. Diaphragmatic hernias have been classified

J. P. Ramspott

janphilipp.ramspott@gmail.com

1 Department of Surgery, Paracelsus Medical University Salzburg, Müllner Hauptstraße 48, 5020 Salzburg, Austria

2 Department of Gynecology and Obstetrics, Münster University Hospital, Münster, Germany

3 Department of Trauma Surgery, BG Trauma Center Murnau, Murnau, Germany into posterolateral, anterior, or central [2]. The posterolateral defect in the lumbocostal triangle (Bochdalek hernia) is the most common type, which was first described by Vincent Alexander Bochdalek in 1848. It is caused by a persistence of the pleuroperitoneal cavity and mostly an incidental finding in children. Congenital diaphragmatic hernias have an incidence of approximately one per 2500 births of whom 70 to $75 \%$ are classified as Bochdalek hernias [3]. Genetic and environmental factors are involved in the development of hernias and they mostly cause respiratory symptoms directly after birth $[4,5]$. The incidence of adult Bochdalek hernias is estimated around 0.17\% [6]. Right-sided Bochdalek hernias are less common than left-sided ones due to faster closure of the right pleuroperitoneal canal and the protective effect of the liver [7]. They mostly present with gastrointestinal or respiratory complaints or asymptomatically. Increased intraabdominal pressure and previous abdominal 
surgery may be precipitating $[7,8]$. Mortality rates in children vary between 42 and $68 \%$ [9, 10], whereas there are only rare data in adults. In contrast to the affected children [11], a clear diagnostic, therapeutic, and follow-up pathway for right-sided Bochdalek hernias in adulthood is missing so far. Due to its rarity, there have been no large retrospective or prospective studies. As these patients mostly present in an emergency setting, there is great need for evidencebased diagnostics and treatment strategies as right-sided Bochdalek hernias are rarely investigated as a separate entity. To the best of our knowledge, no systematic literature review of this rare entity is available to date. In this systematic review, we evaluated the current evidence of published studies describing adult right-sided Bochdalek hernias and evaluated the main patients' characteristics, clinical presentations, and different treatment approaches. Based upon our systematic literature review, we present the current diagnostic, therapeutic, and follow-up management pathway for this rare surgical emergency.

\section{Methods}

\section{Search strategy}

A systematic literature review was conducted in line with the Preferred Reporting Items for Systematic Reviews and Meta-Analyses (PRISMA) guidelines [12]. The electronic databases searched included PubMed and Cochrane library. The search strategy included the following key words: 'right-sided Bochdalek hernia' OR 'right-sided diaphragmatic hernia' from 2004 to 2020. Rout et al. described all cases of adult right-sided Bochdalek hernias published until 2004 [13]. The final search was conducted on 31st of January 2021. Additionally, a snowball search of the included references was performed [14].

\section{Study selection}

In this systematic review only research papers were included if the following inclusion criteria were fulfilled: right-sided non-traumatic Bochdalek hernias and patient's age $\geq 18$ years. Articles describing left- or both-sided Bochdalek hernias, other types of hernias, pregnancy-associated Bochdalek hernias, fetal studies, and traumatic Bochdalek hernias were excluded. Articles not written in English, conference papers, and animal studies were also excluded from this systematic review. First, titles and abstracts were scanned according to the above defined eligibility criteria. Finally, full-text evaluation was performed. In total, 41 studies with 44 cases of right-sided non-traumatic Bochdalek hernias in adults could be identified and included into the analysis (Table 1). No cohort studies or randomized controlled trials were identified.

\section{Data extraction}

The following variables were extracted from each article: patient's age, sex, chief complaint, and past medical history, diagnostic imaging technique, surgical approach and procedure, size of hernia orifice, type of defect closure, herniated organ, need for bowel resection, hernia-related or postoperative complications, and patient's outcome.

\section{Methodological quality assessment}

A modified version of the Newcastle-Ottawa Scale (NOS) designed for case reports was applied to assess the methodological quality of all included studies [15]. The tool consists of eight questions, categorized in four domains: selection, ascertainment, causality, and reporting. Three questions were excluded as they were irrelevant to the included studies. Questions were answered by a binary response (yes or no) independently by JPR and SR. Finally, an overall judgement about the study quality was performed. Studies were of good quality (low risk of bias) when all five questions were fulfilled, moderate when four were fulfilled, and low (high risk of bias) when three or fewer were fulfilled. No disagreements were found between the reviewers.

\section{Statistical analysis}

Statistical analysis was performed using R software, GraphPad Prism (version 9.00 for Windows, GraphPad Software, La Jolla, CA, USA, www.graphpad.com), and Microsoft Office Excel 365. Normality was measured using the Shapiro-Wilk normality test and data were reported accordingly.

\section{Results}

Two databases were searched resulting in 401 records. In total, 341 studies were excluded on title and/or abstract and 19 studies after full-text screening because of missing inclusion or defined exclusion criteria (trauma $n=2$, patient's age $<18$ years $n=4$, other type of hernia $n=2$, pregnancyassociated hernias $n=1$, missing full text $n=1$, non-English literature $n=1$, and others $n=8$ ). After detailed screening only 41 studies of adult right-sided Bochdalek hernias were found to be eligible for this systematic review. The study selection process is shown in the PRISMA flowchart (Fig. 1). No overlapping study populations were identified. The characteristics of the included studies are presented in Table 1. The results of methodological quality assessment are shown in Supplementary Table 1. Overall, eight studies 


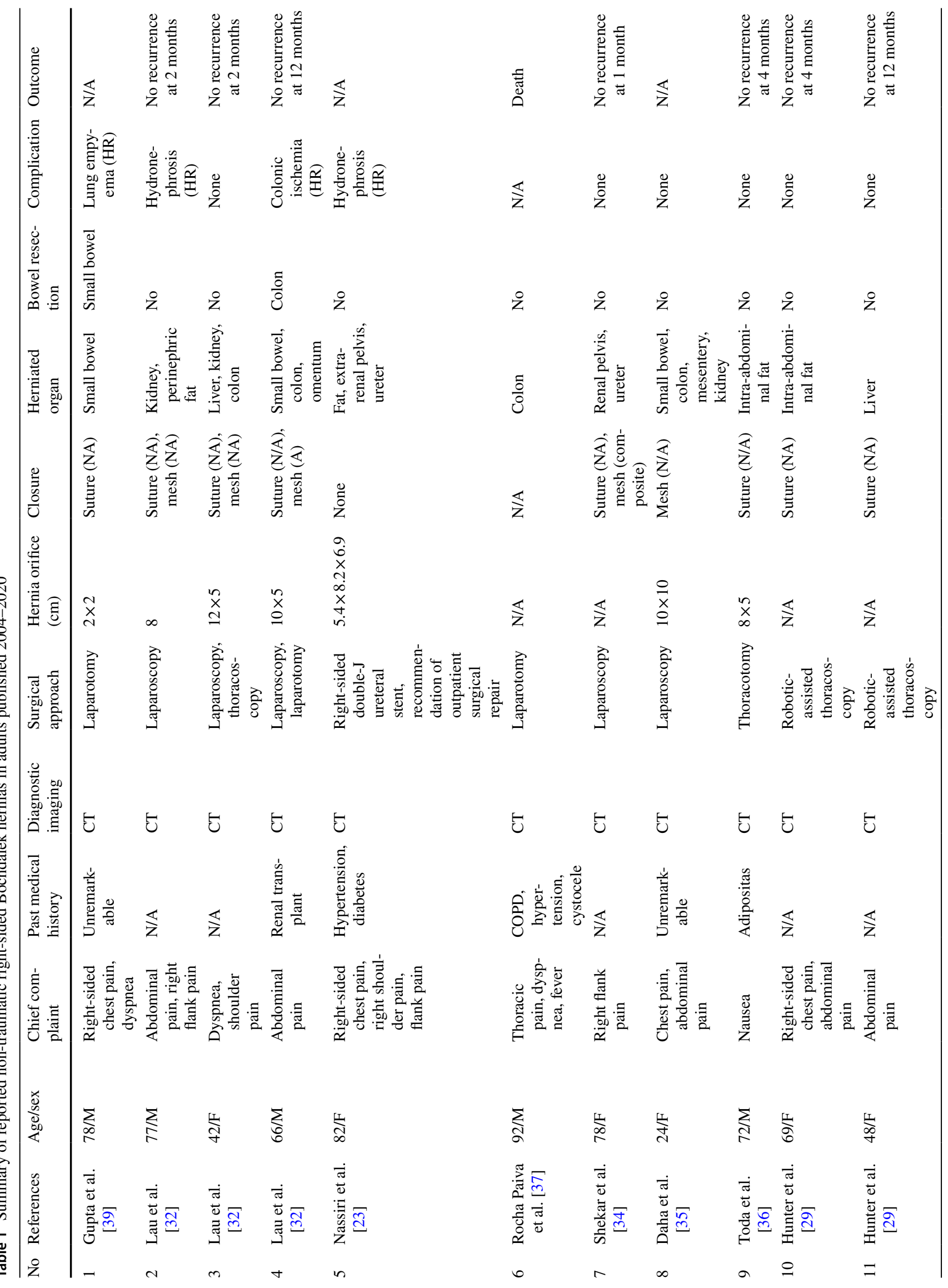




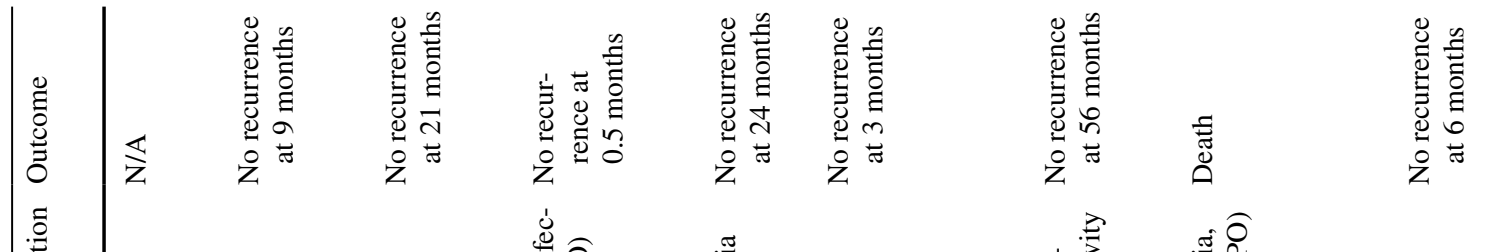

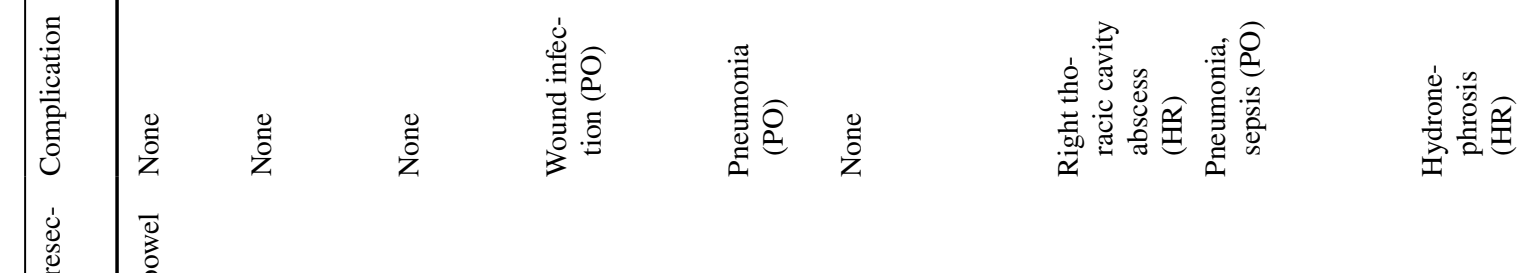

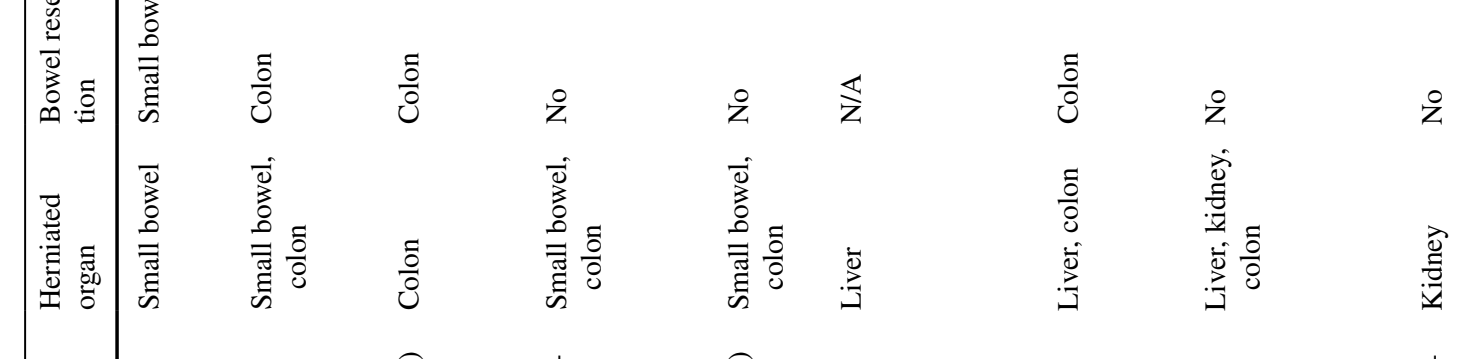

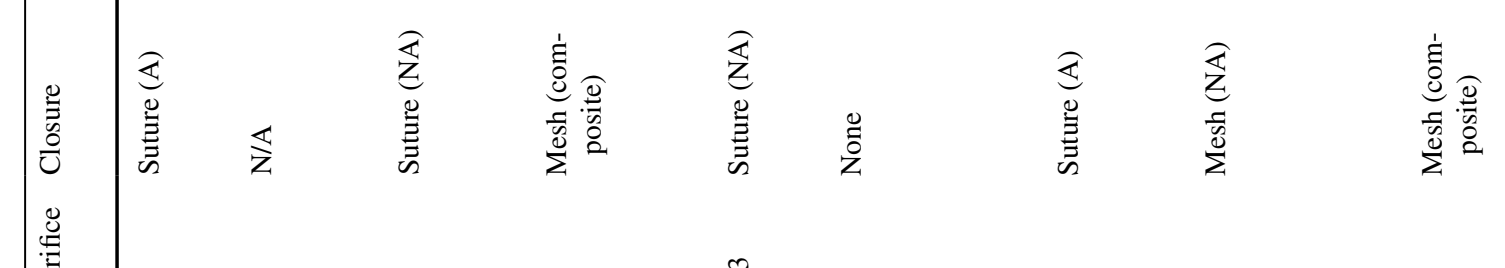

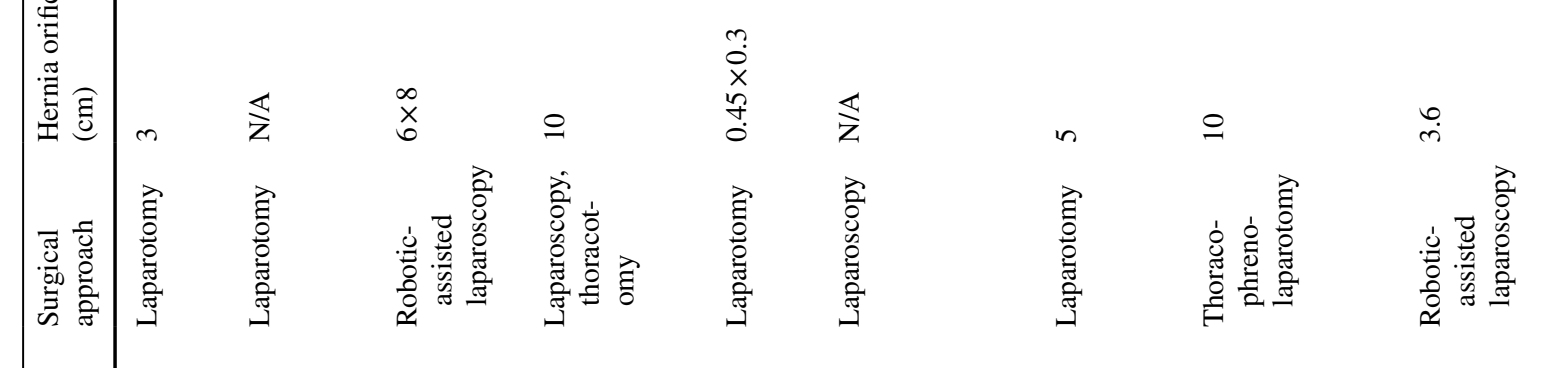

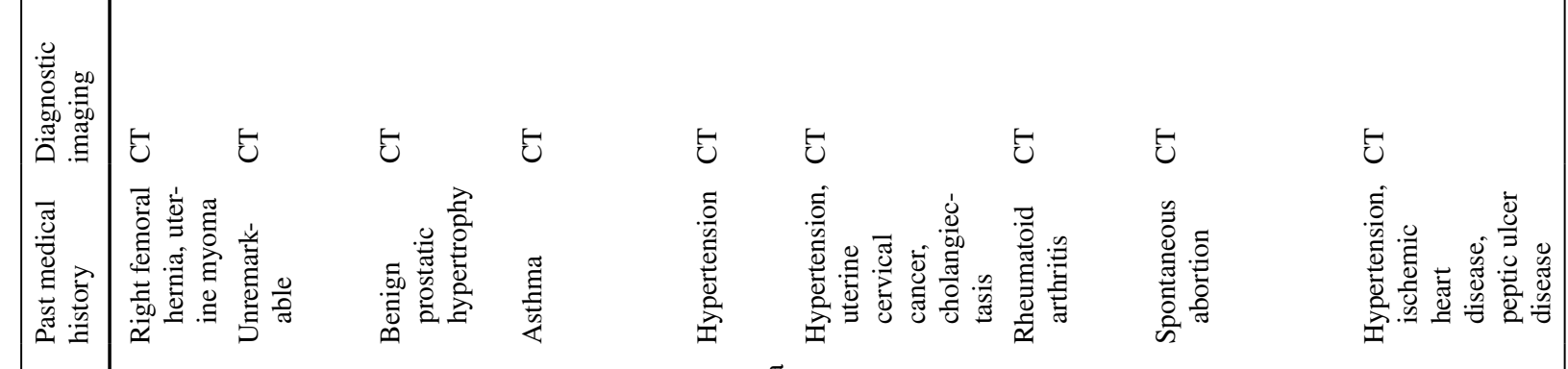

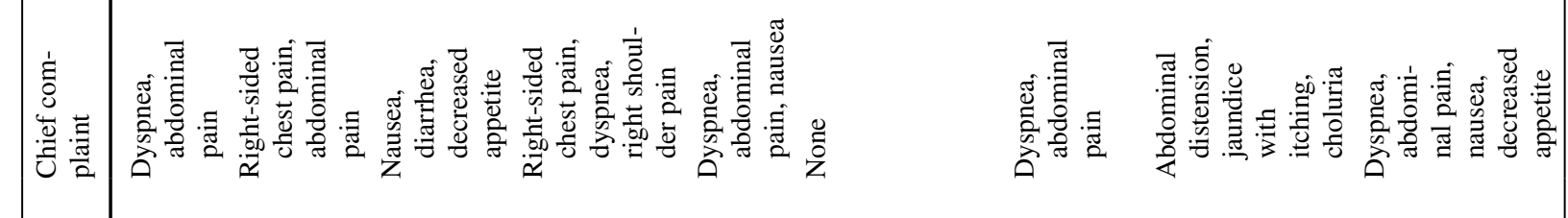

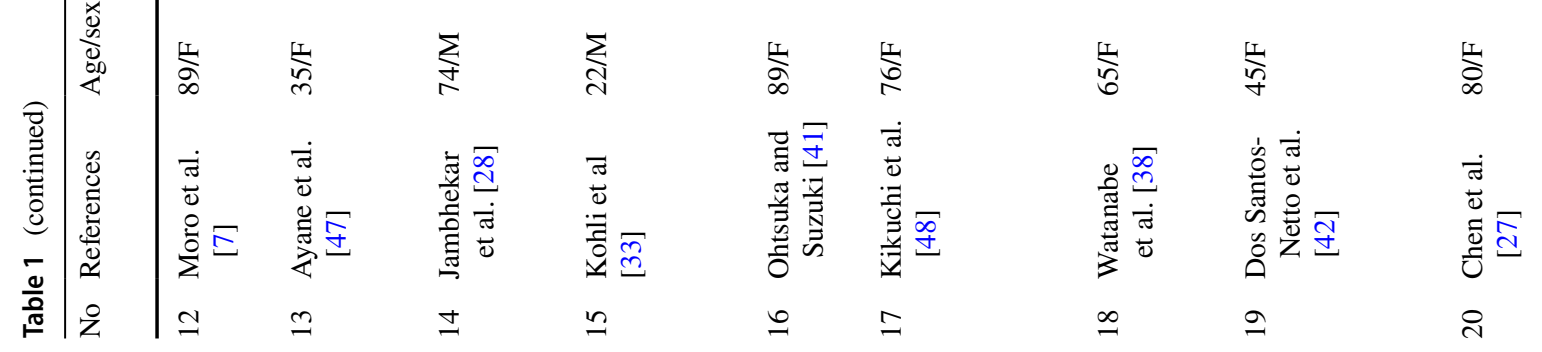




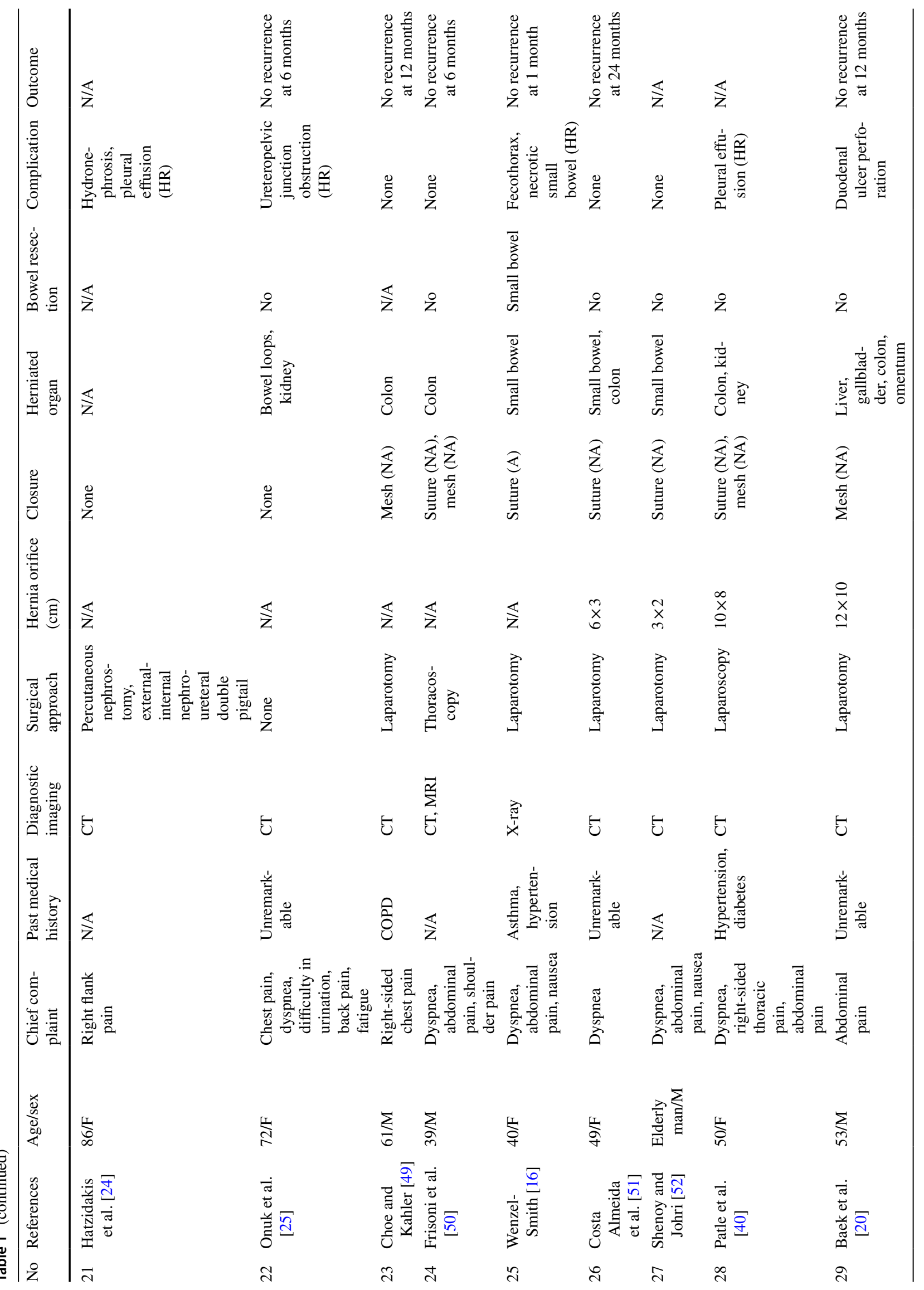




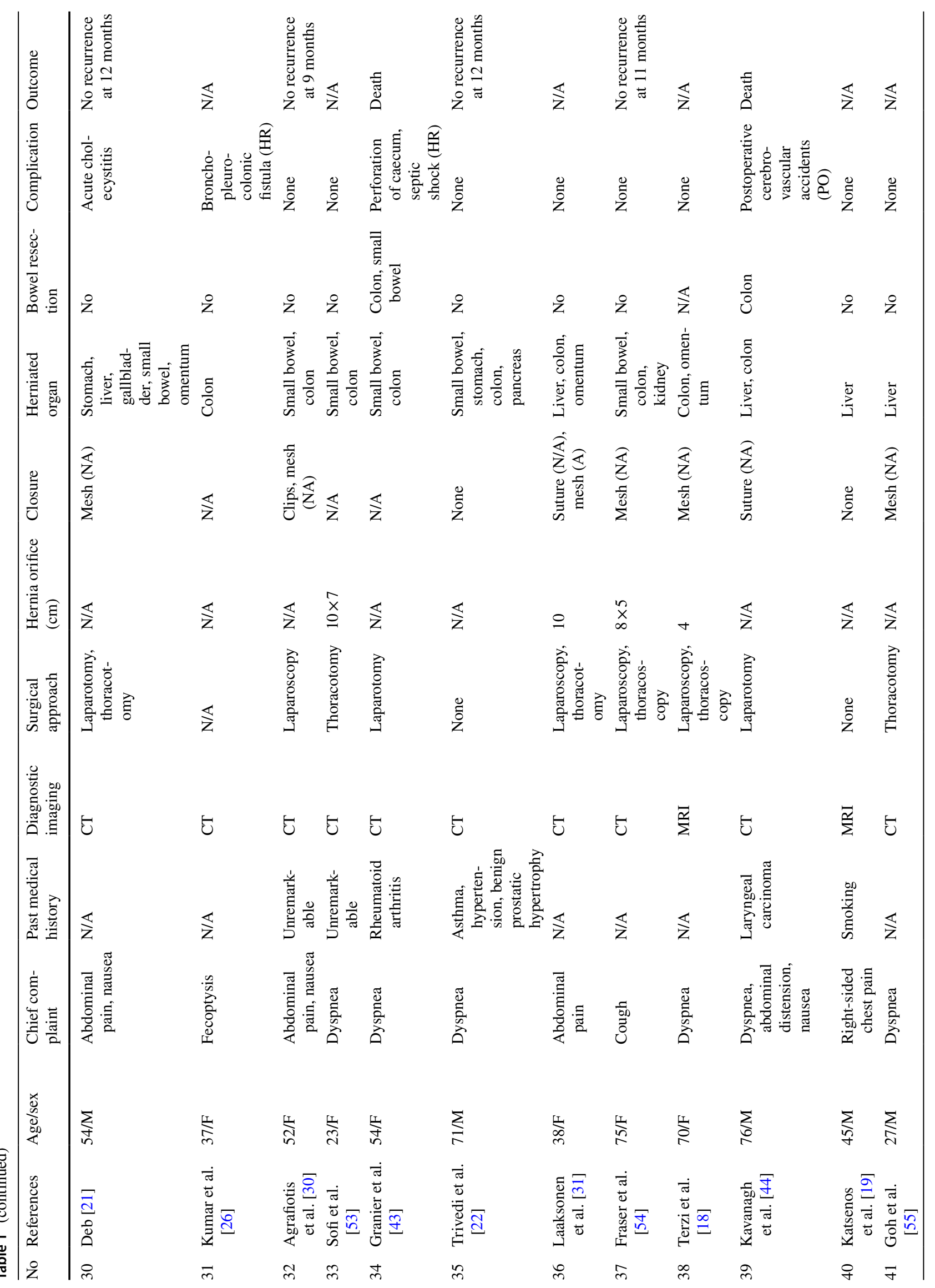


(18\%) were judged as good, 14 (32\%) as moderate, and 22 $(50 \%)$ as low quality.

\section{Patients' baseline characteristics}

Mean age of the included patients was 58 years ranging from 22 to 92 years. Peak ages for right-sided Bochdalek hernias were 40 to 50 and 70 to 80 years (Fig. 2). $61 \%$ of the patients were women $(n=27), 39 \%(n=17)$ were men. Almost half of the patients $(n=21)$ presented with a chief complaint of dyspnea. Abdominal pain was the second most common symptom $(n=19,43 \%)$ whereas chest pain and nausea were only reported in 10 cases (23\%). A minority of patients suffered from shoulder and/or flank pain $(n=8$, $18 \%)$. Five patients (11\%) suffered from a pulmonary disease like chronic obstructive pulmonary disease (COPD) or asthma. Furthermore, analysis of the past medical history revealed hypertension $(n=7,16 \%)$ and diabetes $(n=2,5 \%)$ in some further patients. Ten cases $(23 \%)$ had an unremarkable history (Table 1).

\section{Diagnostic imaging}

Final diagnosis of right-sided Bochdalek hernias in adulthood was mostly performed using computed tomography (CT) scan $(n=39,89 \%)$. In contrast, only two patients (4\%) were diagnosed clinically or via $X$-ray $[16,17]$. In two cases (5\%) magnetic resonance imaging (MRI) led to the final diagnosis $[18,19]$.

\section{Herniated organ and size of hernia orifice}

In most cases, herniation of the following organs was found: colon $(n=23,52 \%)$, small bowel $(n=19,43 \%)$, liver $(n=12$, $27 \%)$, and kidney $(n=8,18 \%)$. Single cases described herniation of other intraabdominal organs like gallbladder $[20,21]$ or pancreas [22]. Only half of the included studies described the size of the hernia orifice $(n=23,52 \%) .65 \%$ $(n=15)$ of them calculated a minimum of a two-dimensional orifice varying from $0.54 \times 0.3 \mathrm{~cm}$ to $12 \times 10 \mathrm{~cm}$.

\section{Treatment strategy and surgical approach}

Almost all reported cases $(n=38,86 \%)$ were treated surgically. One patient was treated with a right-sided double-J ureteral stent due to preoperative hydronephrosis and outpatient surgical repair of the hernia was recommended. Further information about the follow-up was missing [23]. In one case, percutaneous nephrostomy was performed as the patient was not fit enough to undergo surgery. Further details were not described. She was finally discharged with an external-internal nephroureteral double pigtail for treatment of hernia-related hydronephrosis [24]. Three patients 


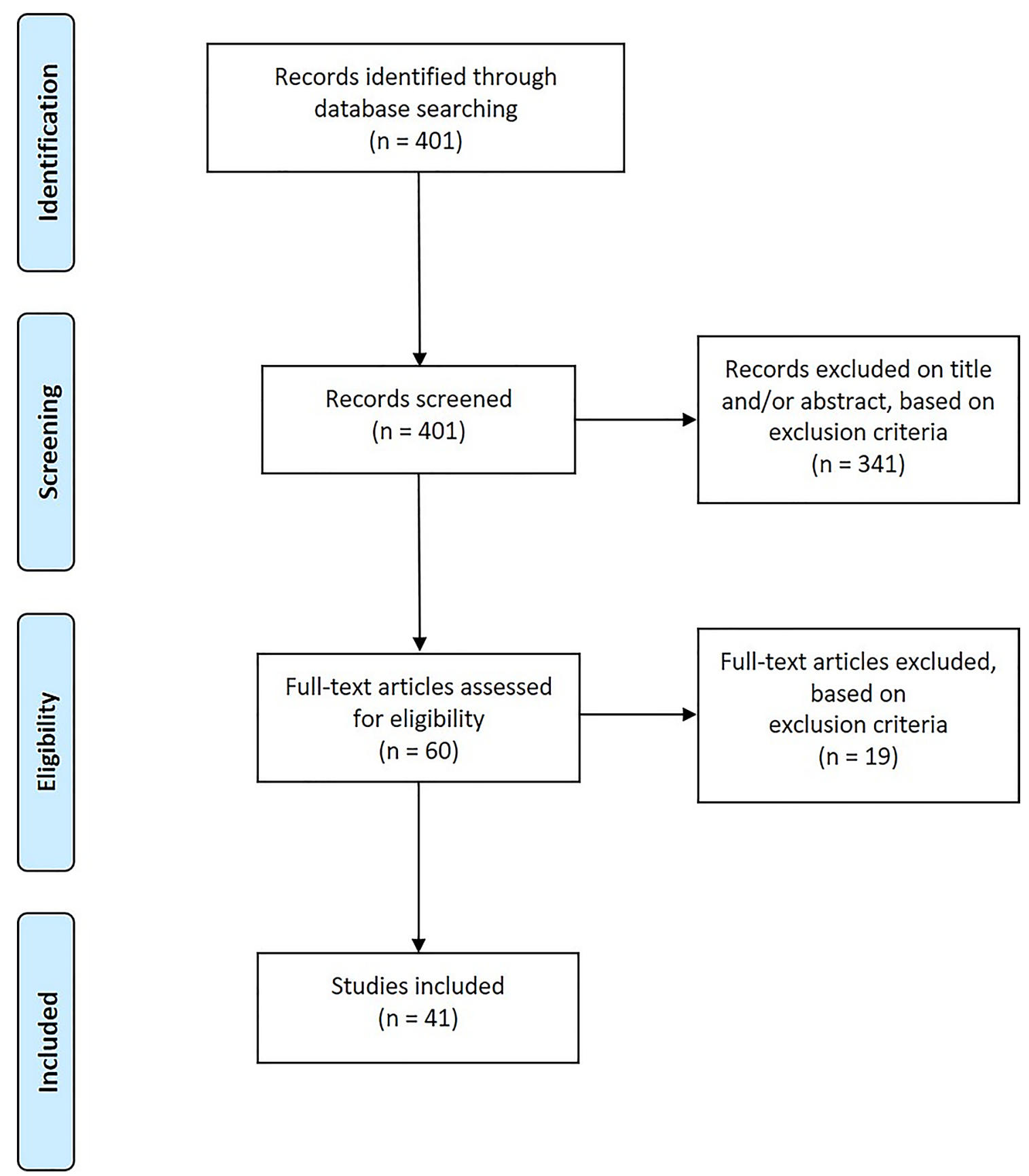

Fig. 1 PRISMA flowchart of study selection

underwent non-interventional management of their Bochdalek hernias. One of them was treated conservatively. Surgical repair was denied due to fear of the operative risks. He did not report any symptoms after 12 months [22]. In one further case, the patient refused any surgical repair and denied any problems 6 months later [25]. In the third case, symptoms resolved a few days after initial presentation in the hospital. A follow-up was not described [19]. No treatment strategy of the diaphragmatic defect was reported in one further case [26]. Most patients underwent an abdominal approach for surgical repair. Laparotomy was performed in $34 \%(n=15)$ and a laparoscopy in $34 \%(n=15)$ of all cases. Two patients (5\%) underwent robotic-assisted laparoscopy $[27,28]$. Only in $16 \%(n=7)$ a thoracotomy, and in $14 \%$ $(n=6)$ a thoracoscopy was performed. Two patients (5\%) were operated by robotic-assisted thoracoscopy [29]. Seven patients $(16 \%)$ underwent a thoracoabdominal approach. If a bowel resection was required, an open approach was more common (nine of ten cases). In one case colon resection 
Fig. 2 Age distribution in patients with right-sided Bochdalek hernias; $x$-axis shows age in years, $y$-axis shows density. Density curve is shown in red. Two peak ages 40 to 50 and 70 to 80 years can be detected
Age distribution

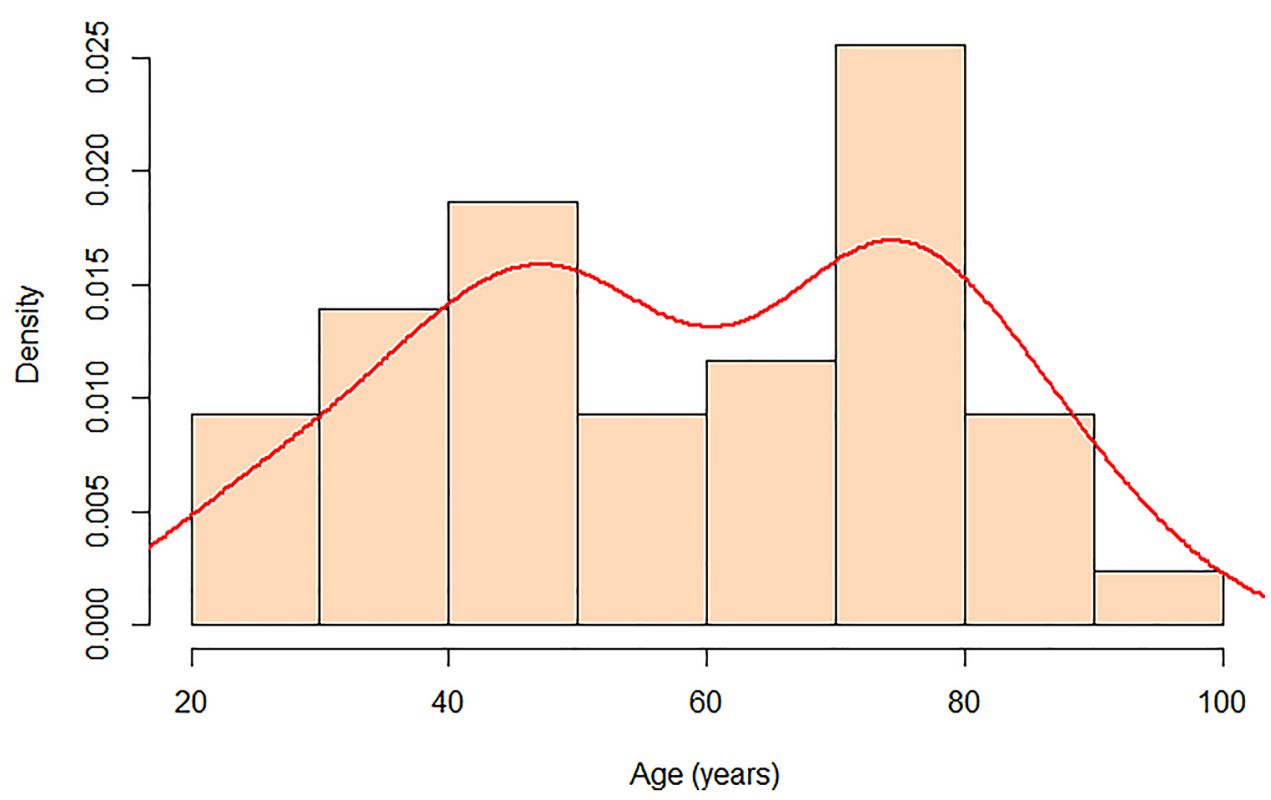

was performed by robotic-assisted laparoscopy [28]. No data about operative time and surgical experience were available.

\section{Type of defect closure}

The most common type of repair was done by direct diaphragmatic sutures in 20 cases (45\%) followed by meshaugmented defect-closure in 19 cases (43\%). A combination of mesh and suture for diaphragmatic defect repair was used in $16 \%(n=7)$. One case reported a combination of clips and mesh [30]. Six cases (14\%) did not report the type of closure. Most patients with a mesh received a non-absorbable mesh $(n=13,68 \%)$. In two cases diaphragmatic defect was repaired by an absorbable mesh $(11 \%)$ [31, 32]. A composite mesh was used in three patients (16\%) [27, 33, 34]. One case did not report the type of mesh [35]. The suture type was mostly non-absorbable $(n=13,65 \%)$ followed by absorbable sutures $(n=4,20 \%)$. Three cases $(15 \%)$ did not describe the type of suture $[31,32,36]$.

\section{Complication}

Twenty-five patients (57\%) did not show any hernia or intervention-related complications. One case did not report any information about difficulties [37]. Complications mostly included a hydronephrosis $(n=4,9 \%)$ due to herniation of ureter or kidney $[6,7,18,19]$. In two of these patients hydronephrosis resolved after surgical treatment $[18,19]$, whereas two other cases did not report any follow-up [6, 7]. In eight patients (18\%) right-sided Bochdalek hernias were associated with thoracic complications: abscess formation [38], lung empyema [39], broncho-pleuro-colonic fistula [26], pleural effusion [24, 40], fecothorax [16], and pneumonia [41, 42]. One patient underwent a surgical approach to the chest and abdomen [42]. Laparotomy was performed in four cases [16, 38, 39, 41], laparoscopy in one case [30]. One patient underwent urological treatment [24] and one further case did not report the surgical procedure [26]. Other herniarelated complications included bowel ischemia $(n=2,4 \%)$ $[16,32]$ and bowel perforation $(n=2,4 \%)$ [20, 43]. Postoperative complications included wound infection $(n=1,2 \%)$ [33] and sepsis $(n=1,2 \%)$ [42]. In ten cases (23\%) colon and/or small bowel resection was performed due to mentioned bowel complications.

\section{Outcome}

Four patients $(9 \%)$ died after the surgical procedure due to pneumonia and sepsis [42], sequelae of bowel perforation [43], or cerebrovascular incidents [44]. One case did not report any specific reason for postoperative death [37]. Median follow-up was 9 months with no recurrence, but more than one-third of the published cases $(n=16)$ did not report any kind of follow-up at all.

\section{Diagnostic, therapeutic, and follow-up management algorithm}

A clear clinical guideline and/or algorithm for right-sided Bochdalek hernias in adults is missing so far. Therefore, 
based upon our comprehensive literature review, we present the current diagnostic, therapeutic, and follow-up management pathway (Fig. 3).

\section{Discussion}

This systematic review demonstrates that there are only very limited studies available investigating the diagnostics, treatment, and follow-up of right-sided Bochdalek hernias in adulthood. However, this review has several strengths. The PRISMA guideline [12] was followed, a snowball search was conducted, and screening and quality assessment of records was performed by two independent reviewers. Most publications which were identified are of moderate to low methodological quality as all of them were case reports. Most reports did not report defect size, surgical treatment details, or long-term follow-up data.

The following conclusions can be conducted from this systematic review. Right-sided Bochdalek hernia in adulthood is a rare surgical entity overall and in numerous cases an emergency. Patients mostly present with dyspnea and/ or abdominal pain. Its masquerading clinical appearance requires rapid diagnostic imaging (gold standard CT) following surgical repair of each symptomatic and/or complicated hernia to decrease high mortality and morbidity rates (Fig. 3). Pregnancy or a medical history of pulmonary diseases may increase intraabdominal pressure and, therefore, precipitate the development of right-sided Bochdalek hernias in adults. Due to missing long-term follow-up data and its rarity, the adequate surgical procedure is unclear so far and only based on a case-by-case basis.

Any clinical or imaging signs of acute incarceration, perforation and/or ileus must lead to emergent surgical management. If surgery is significantly delayed in these situations or if patients are not fit enough to undergo emergent surgery, symptomatic therapy with a highly complicated outcome remains the online available option.

A laparotomy enables sufficient management of visceral complications like perforation, evaluation of bowel perfusion, and management of potential abdominal contamination. Contrarily, only limited exposure of the chest cavity risks not to detect a concomitant pneumothorax, pleural effusion or empyema, or other thoracic-related complications [45]. Repair of the hernia orifice can be easier performed by thoracotomy, particularly in right-sided Bochdalek hernias, in which the liver may mask the diaphragmatic defect [7]. A thoracoabdominal approach permits evaluation and adequate surgical treatment of both cavities and should only be performed if necessary. If so, open approach should be combined with a minimally invasive one depending on technical feasibility. Minimally invasive surgery may be associated with technical difficulties. Necessary expertise

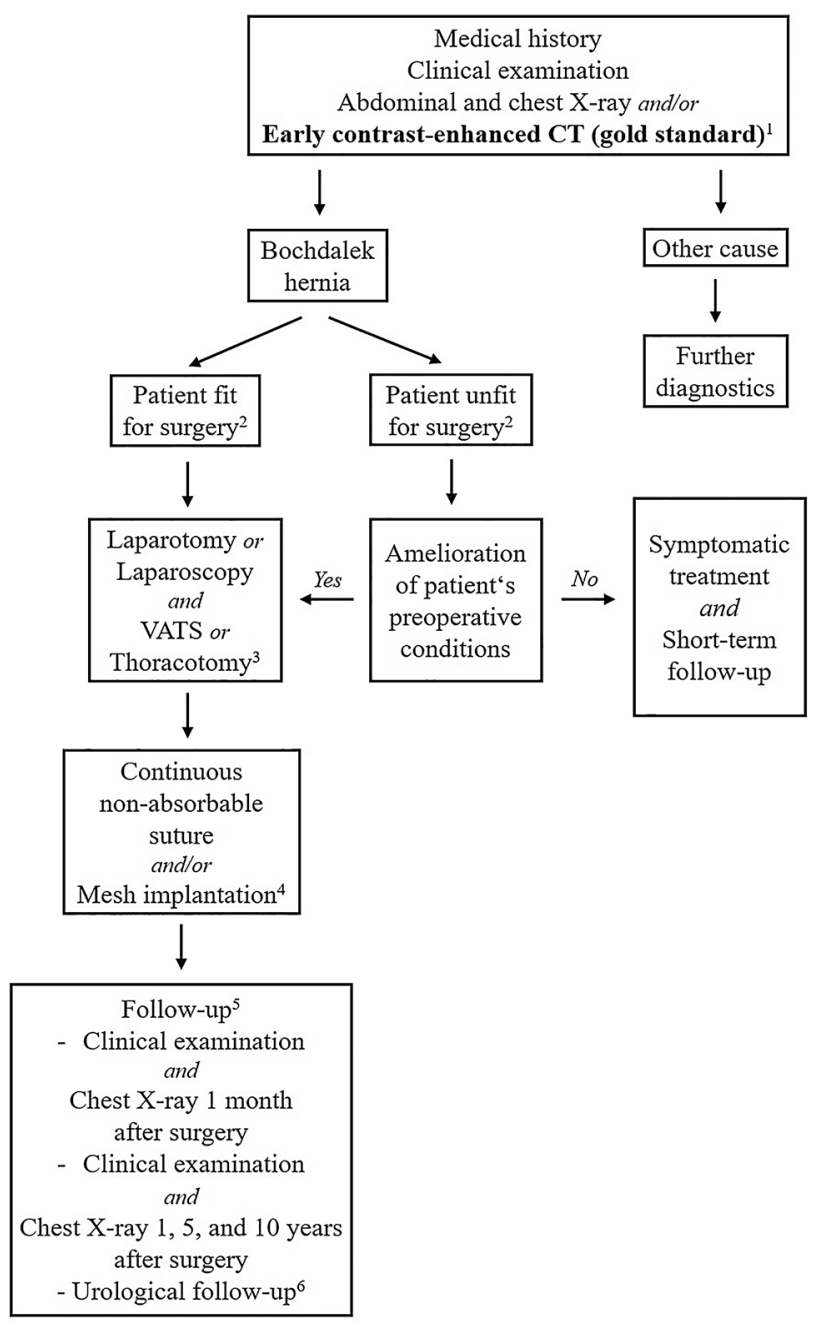

'Pleural and abdominal ultrasound only for exclusion of differential diagnoses if available; Computed tomography (CT); ${ }^{2}$ Consideration of patient's transfer to a higher-level hospital; ${ }^{3}$ Depending on available surgical skills and patient's fitness: Consideration of patient's transfer to a higher-level hospital with thoracic surgery; Video-assisted thoracoscopic surgery (VATS); ${ }^{4}$ Thoracic mesh implantation might be better as the liver avoids sufficient defect overlap; In a contaminated setting mesh implantation should only be considered in case of hernia recurrence; ${ }^{5}$ Record according to the Herniamed Registry [46]; In case of pathological X-ray findings contrast-enhanced computed tomography should be performed; ${ }^{6}$ In case of herniation of ureter or kidney

Fig. 3 Diagnostic, therapeutic, and follow-up management pathway of adult Bochdalek hernias

in advanced thoracoscopy is often not available in general surgical departments, in particular in the often nocturnal emergency setting. In addition, patients with delayed presentation may not be fit enough for thoracoscopy and/ or laparoscopy regarding the risk of anesthesia. Patient's transfer to a higher-level hospital must always be considered if expertise in complex surgery, including two-cavity and thoracic surgery or intensive care is not available. In patients who undergo abdominal approach for right-sided Bochdalek repair it remains unclear if a simultaneous thoracic approach via video-assisted thoracoscopic surgery 
(VATS) or thoracotomy following extensive intrathoracic evaluation and lavages would prevent later development of thoracic complications. Diaphragmatic defects were mostly repaired by direct diaphragmatic sutures and meshaugmentation. For better defect augmentation we strongly recommend non-absorbable suture as well as non-absorbable mesh in accordance with the general principles of hernia surgery. In case of intraabdominal or intrathoracic contamination mesh implantation should only be considered in case of hernia recurrence. The use of the hernia sac to cover the mesh against the respective organs and anti-adhesive meshes could reduce postoperative adhesions.

This review has several limitations. First, most publications, which were identified are of moderate or low methodological quality as all of them were case reports with a low level of evidence. Due to their retrospective character, there might be a selection/publication bias. Second, most reports did not report all relevant details like defect size or surgical treatment. Besides, follow-up was often insufficient or mainly short-term complicating further diagnostic and treatment strategy development. Therefore, there is urgent need for standardized reporting of right-sided Bochdalek hernias in adulthood [46]. Finally, the small number of patients yields the risk to over-interpret the data.

Based upon our literature review, we hereby present the current follow-up algorithm with regular follow-up visits including imaging up to 10 years after surgery. In cases of herniation of ureter and/or kidney, urological consultation is mandatory (Fig. 3). Hernia recurrence after surgical repair has not been described so far, but recurrence obviously must be expected in at least some cases. Current numbers of recurrence should be viewed with caution due to insufficient follow-up data.

\section{Conclusion}

This systematic review underlined that studies investigating diagnostic algorithm, treatment strategy, and follow-up of right-sided Bochdalek hernias in adulthood are of low methodological quality to date. Despite their overall low incidence, this type of hernia tends to occur more frequently in middle-aged and older women mostly presenting with abdominal pain and dyspnea. A rapid and accurate diagnosis following surgical repair is mandatory. Based on the literature available a comprehensive suggested pathway for the emergency management of patients presenting with acutely complicated Bochdalek hernia was developed. Due to the rarity of these hernias, high-quality studies with a sufficient investigation as an own entity are almost impossible to conduct. Instead, observational studies could provide more evidence-based insights. Therefore, data about this entity, patients' characteristics, and their medical work-up must be reported in a standardized manner and/or common database.

Supplementary Information The online version contains supplementary material available at https://doi.org/10.1007/s10029-021-02445-1.

Author contributions All authors contributed to the idea and design of the study. JPR and SR performed the literature search, conducted eligibility screening and quality assessment, and drafted the manuscript. TJ, ML, PS, AG, FM, and KE critically revised the work. All authors read and gave final approval of the manuscript to be published and agreed to be accountable for the content of this manuscript.

Funding Open Access funding enabled and organized by Projekt DEAL.

\section{Declarations}

Conflict of interest All authors declare that they have no competing interests.

Ethical approval Ethical approval is not required for this type of study.

Human and animal rights This article does not contain any studies with human participants or animals performed by any of the authors.

Informed consent Informed consent was not required for this study.

Open Access This article is licensed under a Creative Commons Attribution 4.0 International License, which permits use, sharing, adaptation, distribution and reproduction in any medium or format, as long as you give appropriate credit to the original author(s) and the source, provide a link to the Creative Commons licence, and indicate if changes were made. The images or other third party material in this article are included in the article's Creative Commons licence, unless indicated otherwise in a credit line to the material. If material is not included in the article's Creative Commons licence and your intended use is not permitted by statutory regulation or exceeds the permitted use, you will need to obtain permission directly from the copyright holder. To view a copy of this licence, visit http://creativecommons.org/licenses/by/4.0/.

\section{References}

1. Keijzer R, Puri P (2010) Congenital diaphragmatic hernia. Semin Pediatr Surg 19(3):180-185. https://doi.org/10.1053/j.sempe dsurg.2010.03.001

2. Kotecha S, Barbato A, Bush A, Claus F, Davenport M, Delacourt C, Deprest J, Eber E, Frenckner B, Greenough A, Nicholson AG, Antón-Pacheco JL, Midulla F (2012) Congenital diaphragmatic hernia. Eur Respir J 39(4):820-829. https://doi.org/10.1183/09031 936.00066511

3. Leeuwen L, Fitzgerald DA (2014) Congenital diaphragmatic hernia. J Paediatr Child Health 50(9):667-673. https://doi.org/ 10.1111/jpc. 12508

4. Sperling JD, Sparks TN, Berger VK, Farrell JA, Gosnell K, Keller RL, Norton ME, Gonzalez JM (2018) Prenatal diagnosis of congenital diaphragmatic hernia: does laterality predict perinatal outcomes? Am J Perinatol 35(10):919-924. https://doi.org/10. 1055/s-0037-1617754 
5. Kardon G, Ackerman KG, McCulley DJ, Shen Y, Wynn J, Shang L, Bogenschutz E, Sun X, Chung WK (2017) Congenital diaphragmatic hernias: from genes to mechanisms to therapies. Dis Model Mech 10(8):955-970. https://doi.org/10.1242/dmm.028365

6. Mullins ME, Stein J, Saini SS, Mueller PR (2001) Prevalence of incidental Bochdalek's hernia in a large adult population. AJR Am J Roentgenol 177(2):363-366. https://doi.org/10.2214/ajr.177.2. 1770363

7. Moro K, Kawahara M, Muneoka Y, Sato Y, Kitami C, Makino S, Nishimura A, Kawachi Y, Gabriel E, Nikkuni K (2017) Rightsided Bochdalek hernia in an elderly adult: a case report with a review of surgical management. Surg Case Rep 3(1):109. https:// doi.org/10.1186/s40792-017-0385-0

8. Brown SR, Horton JD, Trivette E, Hofmann LJ, Johnson JM (2011) Bochdalek hernia in the adult: demographics, presentation, and surgical management. Hernia 15(1):23-30. https://doi. org/10.1007/s10029-010-0699-3

9. Mah VK, Zamakhshary M, Mah DY, Cameron B, Bass J, Bohn D, Scott L, Himidan S, Walker M, Kim PC (2009) Absolute vs relative improvements in congenital diaphragmatic hernia survival: what happened to "hidden mortality." J Pediatr Surg 44(5):877_ 882. https://doi.org/10.1016/j.jpedsurg.2009.01.046

10. Colvin J, Bower C, Dickinson JE, Sokol J (2005) Outcomes of congenital diaphragmatic hernia: a population-based study in western Australia. Pediatrics 116(3):e356-363. https://doi.org/ 10.1542/peds.2004-2845

11. Puligandla PS, Skarsgard ED, Offringa M, Adatia I, Baird R, Bailey M, Brindle M, Chiu P, Cogswell A, Dakshinamurti S, Flageole H, Keijzer R, McMillan D, Oluyomi-Obi T, Pennaforte T, Perreault T, Piedboeuf B, Riley SP, Ryan G, Synnes A, Traynor M (2018) Diagnosis and management of congenital diaphragmatic hernia: a clinical practice guideline. CMAJ 190(4):E103-E112. https://doi.org/10.1503/cmaj.170206

12. Moher D, Liberati A, Tetzlaff J, Altman DG (2009) Preferred reporting items for systematic reviews and meta-analyses: the PRISMA statement. PLoS Med 6(7):e1000097. https://doi.org/ 10.1371/journal.pmed.1000097

13. Rout S, Foo FJ, Hayden JD, Guthrie A, Smith AM (2007) Rightsided Bochdalek hernia obstructing in an adult: case report and review of the literature. Hernia 11(4):359-362. https://doi.org/10. 1007/s10029-007-0188-5

14. Greenhalgh T, Peacock R (2005) Effectiveness and efficiency of search methods in systematic reviews of complex evidence: audit of primary sources. BMJ 331(7524):1064-1065. https://doi.org/ 10.1136/bmj.38636.593461.68

15. Murad MH, Sultan S, Haffar S, Bazerbachi F (2018) Methodological quality and synthesis of case series and case reports. BMJ Evid Based Med 23(2):60-63. https://doi.org/10.1136/ bmjebm-2017-110853

16. Wenzel-Smith G (2013) Posterolateral diaphragmatic hernia with small-bowel incarceration in an adult. S Afr J Surg 51(2):73-74. https://doi.org/10.7196/sajs. 1320

17. Owen ME, Rowley GC, Tighe MJ, Wake PN (2007) Delayed diagnosis of infarcted small bowel due to right-sided Bochdalek hernia. Ann R Coll Surg Engl 89(2):W1-2. https://doi.org/10.1308/ $147870807 \times 160407$

18. Terzi A, Tedeschi U, Lonardoni A, Furia S, Benato C, Calabrò F (2008) A rare cause of dyspnea in adult: a right Bochdalek's hernia-containing colon. Asian Cardiovasc Thorac Ann 16(5):e42e44. https://doi.org/10.1177/021849230801600523

19. Katsenos S, Kokkonouzis I, Lachanis S, Psathakis K (2008) Rightsided Bochdalek hernia presenting as a solitary pulmonary nodule. Radiol Case Rep 3(2):114. https://doi.org/10.2484/rcr.v3i2. 114

20. Baek SJ, Kim J, Lee SH (2012) Hepatothorax due to a right diaphragmatic rupture related to duodenal ulcer perforation. World
J Gastroenterol 18(39):5649-5652. https://doi.org/10.3748/wjg. v18.i39.5649

21. Deb SJ (2011) Massive right-sided Bochdalek hernia with two unusual findings: a case report. J Med Case Rep 5:519. https:// doi.org/10.1186/1752-1947-5-519

22. Trivedi PJ, Canavan J, Holloway C, Slater A, Travis S (2010) An unusual case of dyspnoea in an elderly man. BMJ Case Rep. https://doi.org/10.1136/bcr.09.2009.2247

23. Nassiri N, Maas M, Asanad K, Hwang D, Duddalwar V, Bhanvadia S (2020) An 82-year-old female with chest pain radiating to the back and flank. Urol Case Rep 32:101220. https://doi.org/10. 1016/j.eucr.2020.101220

24. Hatzidakis A, Kozana A, Glaritis D, Mamoulakis C (2014) Rightsided Bochdalek hernia causing septic ureteric obstruction. Percutaneous treatment with placement of a nephroureteral double pigtail. BMJ Case Rep. https://doi.org/10.1136/bcr-2014-207247

25. Onuk Ö, Taş T, Şentürk AB, Sinanoğlu O, Balcı MB, Çelik O, Nuhoğlu B (2014) Right-sided Bochdalek hernia with intrathoracic ectopic kidney in an advanced-age adult: a case report. Urol Int 93(3):368-370. https://doi.org/10.1159/000353100

26. Kumar M, Chandra A, Kumar S (2011) Right-sided diaphragmatic hernia complicated with broncho-pleuro-colonic fistula presenting as fecoptysis. BMJ Case Rep. https://doi.org/10.1136/bcr.06.2011. 4296

27. Chen B, Finnerty BM, Schamberg NJ, Watkins AC, DelPizzo J, Zarnegar R (2015) Transabdominal robotic repair of a congenital right diaphragmatic hernia containing an intrathoracic kidney: a case report. J Robot Surg 9(4):357-360. https://doi.org/10.1007/ s11701-015-0530-3

28. Jambhekar A, Robinson S, Housman B, Nguyen J, Gu K, Nakhamiyayev V (2018) Robotic repair of a right-sided Bochdalek hernia: a case report and literature review. J Robot Surg 12(2):351-355. https://doi.org/10.1007/s11701-017-0705-1

29. Hunter LM, Mozer AB, Anciano CJ, Oliver AL, Iannettoni MD, Speicher JE (2019) Robotic-assisted thoracoscopic repair of rightsided Bochdalek hernia in adults: a two-case series. Innovations 14(1):69-74. https://doi.org/10.1177/1556984518823642

30. Agrafiotis AC, Kotzampassakis N, Boudaka W (2011) Complicated right-sided Bochdalek hernia in an adult. Acta Chir Belg 111(3):171-173. https://doi.org/10.1080/00015458.2011.11680 730

31. Laaksonen E, Silvasti S, Hakala T (2009) Right-sided Bochdalek hernia in an adult: a case report. J Med Case Rep 3:9291. https:// doi.org/10.1186/1752-1947-3-9291

32. Lau NS, Crawford M, Sandroussi C (2020) Surgical management of symptomatic right-sided Bochdalek hernias in adults: when is a minimally invasive approach appropriate? ANZ J Surg 90(6):1075-1079. https://doi.org/10.1111/ans.15830

33. Kohli N, Mitreski G, Yap CH, Leong M (2016) Massive symptomatic right-sided Bochdalek hernia in an adult man. BMJ Case Rep. https://doi.org/10.1136/bcr-2016-217432

34. Shekar PA, Reddy D, Kochhar G, Dumra A, Ks S (2020) Herniation of the right renal pelvis through a posterolateral diaphragmatic defect (Bochdalek hernia). Urology 137:e10-e11. https:// doi.org/10.1016/j.urology.2019.12.009

35. Daha SK, Karn A, Shrestha N, Shrestha N, Paudyal S, Giri N (2019) A female with right-sided thoracic kidney with Bochdalek hernia: a case report. JNMA J Nepal Med Assoc 57(220):464466. https://doi.org/10.31729/jnma.4747

36. Toda M, Yamamoto A, Iwata T (2019) Right-sided Bochdalek hernia containing retroperitoneal fat in the elderly: report of a case. Surg Case Rep 5(1):81. https://doi.org/10.1186/ s40792-019-0637-2

37. Rocha Paiva D, Casanova D, Martins H, Cerqueira M, Formigo M, Miranda O, Cotter J (2020) A rare cause of dyspnoea: 
right-sided Bochdalek hernia in an adult. Eur J Case Rep Intern Med 7(7):001531. https://doi.org/10.12890/2020_001531

38. Watanabe M, Ishibashi O, Watanabe M, Kondo T, Ohkohchi N (2015) Complicated adult right-sided Bochdalek hernia with Chilaiditi's syndrome: a case report. Surg Case Rep 1(1):95. https://doi.org/10.1186/s40792-015-0100-y

39. Gupta S, Warrell D, Smith L, Williams GL (2020) Strangulated right-sided diaphragmatic hernia presenting and treated as lung empyema: beware of the differential diagnosis. BMJ Case Rep. https://doi.org/10.1136/bcr-2019-233440

40. Patle NM, Tantia O, Prasad P, Das PC, Khanna S (2013) Laparoscopic repair of right sided Bochdalek hernia - a case report. Indian J Surg 75(Suppl 1):303-304. https://doi.org/10.1007/ s12262-012-0698-y

41. Ohtsuka Y, Suzuki TH (2017) Right-sided Bochdalek hernia in an elderly patient: a case review of adult Bochdalek hernias from 1982 to 2015 in Japan. Acute Med Surg 4(2):209-212. https://doi. org/10.1002/ams 2.249

42. dos Santos-Netto JM, Oliveira CV, Sousa MG (2015) Right-sided Bochdalek hernia in adult associated with cholestatic syndrome: case report. Arq Bras Cir Dig 28(4):299-301. https://doi.org/10. 1590/s0102-6720201500030023

43. Granier V, Coche E, Hantson P, Thoma M (2010) Intrathoracic caecal perforation presenting as dyspnea. Case Rep Med 2010:296730. https://doi.org/10.1155/2010/296730

44. Kavanagh DO, Ryan RS, Waldron R (2008) Acute dyspnoea due to an incarcerated right-sided Bochdalek's hernia. Acta Chir Belg 108(5):604-606. https://doi.org/10.1080/00015458.2008.11680 298

45. Suzuki T, Okamoto T, Hanyu K, Suwa K, Ashizuka S, Yanaga K (2014) Repair of Bochdalek hernia in an adult complicated by abdominal compartment syndrome, gastropleural fistula and pleural empyema: report of a case. Int J Surg Case Rep 5(2):82-85. https://doi.org/10.1016/j.ijscr.2013.12.018

46. Stechemesser B, Jacob DA, Schug-Paß C, Köckerling F (2012) Herniamed: an internet-based registry for outcome research in hernia surgery. Hernia 16(3):269-276. https://doi.org/10.1007/ s10029-012-0908-3

47. Ayane GN, Walsh M, Shifa J, Khutsafalo K (2017) Right congenital diaphragmatic hernia associated with abnormality of the liver in adult. Pan Afr Med J 28:70. https://doi.org/10.11604/pamj. 2017.28.70.11249
48. Kikuchi S, Nishizaki M, Kuroda S, Kagawa S, Fujiwara T (2016) A case of right-sided Bochdalek hernia incidentally diagnosed in a gastric cancer patient. BMC Surg 16(1):34. https://doi.org/10. 1186/s12893-016-0145-2

49. Choe CH, Kahler JJ (2014) Herniation of the lung: a case report. J Emerg Med 46(1):28-30. https://doi.org/10.1016/j.jemermed. 2013.08.040

50. Frisoni R, Germain A, Ayav A, Brunaud L, Bresler L (2014) Thoracoscopic treatment of a right Bochdalek hernia in an adult (with video). J Visc Surg 151(3):239. https://doi.org/10.1016/j. jviscsurg.2014.03.002

51. Costa Almeida CE, Reis LS, Almeida CM (2013) Adult rightsided Bochdalek hernia with ileo-cecal appendix: Almeida-Reis hernia. Int J Surg Case Rep 4(9):778-781. https://doi.org/10. 1016/j.ijscr.2013.06.006

52. Shenoy KR, Johri G (2013) Congenital right Bochdalek hernia presenting as emergency in old age: a case report. Indian J Surg 75(Suppl 1):255-256. https://doi.org/10.1007/s12262-012-0570-0

53. Sofi FA, Ahmed SH, Dar MA, Nabhi DG, Mufti S, Bhat MA, Tabassum PN (2011) Nontraumatic massive right-sided Bochdalek hernia in an adult: an unusual presentation. Am J Emerg Med 29(3):356.e355-357.e355. https://doi.org/10.1016/j.ajem. 2010.03.034

54. Fraser JD, Craft RO, Harold KL, Jaroszewski DE (2009) Minimally invasive repair of a congenital right-sided diaphragmatic hernia in an adult. Surg Laparosc Endosc Percutan Tech 19(1):e57. https://doi.org/10.1097/SLE.0b013e318195c42e

55. Goh BK, Teo MC, Chng SP, Soo KC (2007) Right-sided Bochdalek's hernia in an adult. Am J Surg 194(3):390-391. https://doi. org/10.1016/j.amjsurg.2006.09.039

56. Luo HF, Lei T, Wang HJ, Tan G, Wang ZY (2007) Non-traumatic diaphragmatic hernia of the liver in an adult: a case report. Hepatobiliary Pancreat Dis Int 6(2):219-221

57. Rosen MJ, Ponsky L, Schilz R (2007) Laparoscopic retroperitoneal repair of a right-sided Bochdalek hernia. Hernia 11(2):185188. https://doi.org/10.1007/s10029-006-0162-7

Publisher's Note Springer Nature remains neutral with regard to jurisdictional claims in published maps and institutional affiliations. 